\title{
Is spending time in screen-based sedentary behaviors associated with less physical activity: a cross national investigation
}

\author{
Ole Melkevik*1, Torbjørn Torsheim ${ }^{1}$, Ronald J lannotti² and Bente Wold ${ }^{1}$
}

\begin{abstract}
Background: In Australia and the USA, national guidelines exist for limiting children's screen-exposure to two hours per day. This study aims to determine whether exceeding the suggested guidelines for screen-based sedentary behavior is associated with reduced levels of physical activity across different geographical regions.

Methods: Data material were taken from the 2005/2006 survey of "Health Behaviour in School-aged Children (HBSC) study; A WHO cross-National Survey". Data were collected through questionnaires from 11-,13- and,15-year olds. The final sample included 200,615 adolescents from 39 different countries in Europe and North America. Gender and country stratified analyses regressed time spent in leisure-time vigorous physical activity (VPA) and days of 60 minutes moderate to vigorous physical activity (MVPA) on time spent in screen-based sedentary behaviors. To simplify interpretation, the estimates from each country were pooled using a meta-analytic procedure.

Results: Exceeding 2 hrs of daily total screen-time was negatively associated with MVPA for both boys and girls, and with VPA for girls. When investigating the different types of screen-based behaviors separately, exceeding 2 hrs daily of TV viewing was associated with less MVPA for both boys and girls and less VPA for girls. Gaming was associated with less MVPA and VPA for boys, and non-gaming computer use was associated with higher levels of VPA for both genders. Stronger negative associations between physical activity and screen-based sedentary behaviors were found in countries where mean levels of physical activity were relatively high. The association between physical activity and sedentary behavior was not significantly associated with national levels of screen-based sedentary behaviors.

Conclusions: The displacement mechanism does not appear to be universal across countries. On a national level, negative associations between physical activity and screen-based sedentary behaviors are less likely to be found in countries with relatively low levels of physical activity. Consequently, national guidelines for limiting children and adolescents time in screen-based sedentary behavior may not be conducive to increasing levels of physical activity in all countries.
\end{abstract}

\section{Background}

The growing number of attractive sedentary pursuits such as satellite TV, high-speed internet entertainment, and computer- and video-games has become a concern as some studies have identified screen-based behaviors to be positively associated with overweight, obesity and metabolic risk among children and adolescents [1-4]. One of the ways these screen-based sedentary behaviors have been hypothesized to influence health is through displac-

\footnotetext{
* Correspondence: ole.melkevik@psyph.uib.no

1 University of Bergen, Faculty of Psychology, Christiesgate 13, N-5015 Bergen, Norway

Full list of author information is available at the end of the article
}

ing time that could otherwise have been used for physical activity [5-7]. As children and adolescents who are physically active are less likely to suffer from numerous health risks such as adiposity [5,8], metabolic risk [3], and diabetes [8], it is of great importance to identify factors that could possibly limit a physically active lifestyle.

While several studies have investigated the relationship between physical activity and sedentary behaviors, most of these, including a large scale meta-analysis by Marshall and colleagues [9], have found time spent in sedentary behaviors to be largely uncorrelated with physical activity. 
Despite limited evidence in support of a displacement mechanism, national health authorities in both USA [10] and Australia [11] have implemented national guidelines suggesting that parents should limit their children's screen-exposure to two hours per day or less. While the US guidelines, aim to limit time spent watching TV due to associations between television viewing, exposure to violence, food advertising and various health-outcomes [10], the Australian recommendations are included in their national efforts to increase physical activity among children and adolescents targeting a broader range of screen-based behaviors including both computer gaming and surfing the internet as well as TV/video viewing.

Although these guidelines are exclusively directed at the population of the respective countries, they represent a new approach which could inspire other similar measures in other countries. This is not unproblematic as some cross-national studies [12,13] have identified great variation in how much time adolescents in different parts of Europe and North America spend in different relevant leisure time activities. In light of the potential introduction of national recommendations in other countries, it would thus be important to investigate whether the types of behaviors are associated differently, or if associations are stable across countries.

In light of the reviewed literature, the current study aims to investigate whether exceeding the suggested guidelines of 2 hrs daily of screen-based sedentary behaviors is associated with less time spent in vigorous physical activity (VPA) during leisure time, or with fewer days meeting the recommended 60 minutes of daily moderate to vigorous physical activity (MVPA) among the countries participating in the 2005/06 HBSC survey.

\section{Methods \\ Sample}

The data used in this study were collected as a part of the 2005/2006 survey of "Health Behaviour in School-aged Children (HBSC) study; A WHO Cross-National Survey". Nationally representative samples were selected with school or class being the sampling unit and samples were stratified to ensure national representation. The international research protocol was followed within each country to ensure consistency in survey instruments, consent, data collection and processing procedures [14]. Surveys were administered by the class teachers, participation was voluntary, and anonymity and confidentiality of the participants were ensured.

A total of 205,939 11-, 13- and 15-year old children participated across 41 different countries. Participants from Malta and Portugal were not included in the final analysis as these countries did not include all relevant variables in their national surveys. Thus, the final sample included 200,615 adolescents from 39 different countries of which
$49 \%$ were boys and $51 \%$ were girls. Response rates are not entirely comparable between the different countries due to differences in sampling procedures. Nevertheless, when taking these differences into account, both school/ class and pupil response rates are estimated to exceed $70 \%$ in the majority of countries/regions [15]. More details on the HBSC study procedures can be found elsewhere $[15,16]$.

\section{Measures and constructs}

Time spent in screen-based sedentary behaviors were assessed through three items: "About how many hours a day do you usually watch television (including videos) in your free time?", "About how many hours a day do you play PC-games or TV-games (Playstation, Xbox, GameCube etc.) in your free time?" and "About how many hours per day do you use a PC for chatting online, surfing the internet, writing emails, homework etc. in your free time". The following nine response options were the same for all three questions: "None at all", "About half an hour a day", "About 1 hour a day", "About 2 hours a day", "About 3 hours a day", "About 4 hours a day", "About 5 hours a day", "About 6 hours a day", "About 7 or more hours a day". Vereecken and colleagues [17] evaluated test-retest reliability and relative validity (7-day TV-diary) of the item assessing hours spent watching TV and found no systematic difference was identified between test and retest (Intraclass correlations between test-retest: $\mathrm{ICC}=$ .76 for boys and ICC $=.54$ for girls. Between the test and the diary: $\mathrm{ICC}=.36$ for boys and $\mathrm{ICC}=.54$ for girls) The reported time adolescents usually spent watching TV was found to exceed the time reported in the TV diary by approximately one hour per day for boys, and half an hour for girls The validity of the item reflecting TV/PC gaming has, to the authors' knowledge, not been investigated.

The items assessing screen-based sedentary behaviors were dichotomized in order to test whether exceeding the recommended cutoff of 2 hrs or less daily for screenbased sedentary behaviors influenced the level of VPA or MVPA in the sample. The following items were coded 0 : "None at all", "About half an hour a day", "About 1 hour a day", "About 2 hours a day". Responses of three hours or more were considered to exceed the daily recommendations and were coded 1. In the discussion, these groups are referred to as low and high users, respectively.

In order to investigate the associations between the cumulative time spent in screen-based sedentary behaviors and physical activity, the items assessing screen-time were first recoded to be able to use them as continuous variables. "None at all" was coded 0 , "About half an hour a day" was coded .5, "About 1 hour a day" was coded 1, "About 2 hours a day" was coded 2 etc. Then these variables were added into a sum-score and dichotomized, 
scores of 2 or less were coded 0 , and scores above 2 were coded 1.

Leisure time vigorous physical activity (VPA) was assessed by the question "Outside school hours, how many hours per week do you usually exercise so much that you get out of breath or sweat?." The response categories were: "none", "about 30 minutes", "1 hr", "2-3 hrs", "4-6 hrs", " $\geq 7$ hrs". This item has been found to have at least partial validity as Booth et al. [18] found that adolescents who reported higher levels of VPA outperformed those with lower VPA on a running test. The responses were recoded in order to increase the interpretability of the results. "None" was coded 0 , "about 30 minutes" was coded .5, "1 hr" was coded 1, "2-3 hrs" was coded 2.5, "4-6 hrs" was coded 5 , and finally " $\geq 7$ hrs" was coded 7 .

Moderate to vigorous physical activity (MVPA) was measured by the item "Over the past 7 days how many days were you physically active for a total of at least 60 minutes?" Prochaska and colleagues [19] found this question to be reliable and to have acceptable validity in comparison with accelerometer data.

The Family Affluence Scale (FAS II) was used to measure socioeconomic status among the participants [20]. This is a composite score consisting of four items: "Does your family own a car, van or truck?", "Do you have your own bedroom for yourself?", "During the past 12 months, how many times did you travel away on holiday with your family?", "How many computers do your family own?" Having been found to have higher associations with various health variables level than commonly used economic indicators and having demonstrated good criterion validity, the FAS II is suggested to be a valid and reliable indicator of adolescent socio-economic status $[20,21]$.

\section{Statistical Analyses}

All analyses were performed with STATA (version 10.01 intercooled). The descriptive tables were done with the svy, vec (linearlized) command with school-class as the level 2 sampling unit. Country and gender stratified, svyadjusted linear regression analysis, also with school-class as level 2 sampling unit, was done to produce the estimates which would be used in the meta-analysis. Linear regression was chosen due to the large sample size and reasonably normal-distribution of the different dependent variables.

The first step in the analysis was to regress weekly hours of VPA and days of MVPA on the dummy variables indicating that the individual reported spending more than 2 hrs daily in cumulative and individual screenbased sedentary behaviors. Separate analyses were done for exceeding more than 2 hrs daily in cumulative screenbased sedentary behaviors, and for the three separate subtypes of screen-behaviors. The TV, Gaming and PCuse estimates were mutually adjusted and all regression estimates were controlled for age and family affluence effects. The coefficients in the results should be read as the predicted change in hours of weekly VPA, and in days of 60 min MVPA.

The second step in the analysis was to use coefficients and standard errors from these regression analyses by the fixed-effects meta-analytic approach, metan [22], treating each country as a separate study and using weights based upon the estimated standard errors. Pooled effects were calculated both for the entire sample as well as for the different geographical regions. The estimates for each individual country were saved and used as dependent variables in the meta-regression. While the estimates were saved per country, only regional pooled estimates are presented in the results in order to limit the size of the tables.

A meta-regression was conducted in order to investigate whether the heterogeneity in the associations beetween physical activity and screen-based sedentary behaviors could be due to national differences in mean levels of the respective behaviors. This was done by regressing the country-specific coefficients from the meta-analysis on the mean levels of the respective type of screen-based sedentary behaviors and physical activity. Estimates were adjusted for the time of year data was collected, reducing the possibility of bias due to data collection in warmer or colder months.

\section{Results}

Table 1 shows the regions, countries principal investigators and the $\mathrm{N}$ for each respective country included in the current study. The table also includes the time of year the data was collected.

Additional file 1 shows the percentages of adolescents who report more than 2 hrs daily in cumulative screenbased sedentary behaviors, in each of the screen-based behaviors individually, and mean levels of VPA and MVPA across regions, gender and age. The results show considerable variation in all variables across regions as well as age and gender differences. Gender and age differences were all statistically significant $(\mathrm{p}<.000)$ as indicated by ANOVA's for differences in MVPA and VPA, and for chi-square tests for differences in the screenbased sedentary behaviors.

Regionally, the Baltic countries had the highest prevalence of high use for cumulative screen-time and all the individual screen-based behaviors, although the prevalence of high PC-use was the same in the US (22\%). The region with the lowest prevalence of cumulative highscreen use was central Europe. Adolescents from the Nordic countries reported less high-use of TV and were together with the US adolescents relatively less likely to spend more than 2 hrs daily playing PC/video games. 
Table 1: HBSC countries included in the current study, data collection dates, PI's and N.

\begin{tabular}{|c|c|c|c|}
\hline Country (Principal Investigator) & Data collection dates & Year & $\mathbf{N}$ \\
\hline \multicolumn{4}{|l|}{ North America } \\
\hline Canada (Boyce) & November 2005-June & 2006 & 5930 \\
\hline USA (lannotti) & January-May & 2006 & 3892 \\
\hline \multicolumn{4}{|l|}{ Nordic Countries } \\
\hline Denmark (Due) & February-March & 2006 & 5741 \\
\hline Finland (Tynjälä) & March-May & 2006 & 5249 \\
\hline Greenland (Niclasen) & March-April & 2006 & 1366 \\
\hline Iceland (Bjarnason) & February-March & 2006 & 9540 \\
\hline Norway (Samdal) & December 2005-January & 2006 & 4711 \\
\hline Sweden (Marklund) & November-December & 2005 & 4415 \\
\hline \multicolumn{4}{|l|}{ British Isles } \\
\hline England (Morgan) & September-October & 2006 & 4783 \\
\hline Ireland (Gabhainn) & April-June & 2006 & 4894 \\
\hline Scotland (Currie) & February-March & 2006 & 6190 \\
\hline Wales (Roberts) & January-March & 2006 & 4409 \\
\hline \multicolumn{4}{|l|}{ Central Europe } \\
\hline Austria (Dür) & February-March & 2006 & 4848 \\
\hline Belgium-Flemish (Maes) & March-June & 2006 & 4311 \\
\hline Belgium-French (Piette) & January-February & 2006 & 4476 \\
\hline Switzerland (Kuntsche) & January-March & 2006 & 4621 \\
\hline Germany (Ravens-Sieberer) & January-July & 2006 & 7274 \\
\hline Luxembourg (Wagener) & February-May & 2006 & 4387 \\
\hline Netherlands (Vollebergh) & September-November & 2005 & 4278 \\
\hline \multicolumn{4}{|l|}{ Baltic Countries } \\
\hline Estonia (Aasvee) & February-March & 2006 & 4484 \\
\hline Lithuania (Zaborskis) & March-April & 2006 & 5632 \\
\hline Latvia (Pudule) & February-April & 2006 & 4245 \\
\hline \multicolumn{4}{|l|}{ Eastern Europe } \\
\hline Bulgaria (Vasileva) & March & 2006 & 4854 \\
\hline Czech Republic (Csémy) & May-June & 2006 & 4782 \\
\hline Hungary (Németh) & April-May & 2006 & 3532 \\
\hline Romania (Baban) & March-May & 2006 & 4684 \\
\hline Russian Federation (Komkov) & March-April & 2006 & 8231 \\
\hline Slovakia (Morvicova) & n.a & n.a & 3882 \\
\hline Ukraine (Balakireva) & January-February & 2006 & 5069 \\
\hline Poland (Mazur) & February-April & 2006 & 5489 \\
\hline \multicolumn{4}{|l|}{ Southern Europe } \\
\hline Spain (Rodriguez Moreno) & May & 2006 & 8891 \\
\hline France (Godeau) & March-June & 2006 & 7155 \\
\hline Greece (Kokkevi) & March-April & 2006 & 3715 \\
\hline Croatia (Kuzman) & April & 2006 & 4968 \\
\hline Israel (Harel-Fisch) & May-June & 2006 & 5686 \\
\hline Italy (Cavallo) & May & 2006 & 3951 \\
\hline Macedonia (Chonteva) & April-May & 2006 & 5281 \\
\hline Slovenia (Jeriček) & February-March & 2006 & 5130 \\
\hline \multirow[t]{2}{*}{ Turkey (Ercan) } & May-June & 2006 & 5639 \\
\hline & Total N & & 200615 \\
\hline
\end{tabular}


For physical activity, adolescents from Central Europe and the Nordic countries reported the highest levels of VPA with slightly less than 3 hrs weekly. The lowest levels of VPA was reported among adolescents in Southern Europe, Eastern Europe and the Baltic countries where the mean time spent in leisure time VPA were about $2 \mathrm{hrs}$ weekly. Southern and Eastern European adolescents also reported the lowest levels of MVPA with about 3.9 days weekly whereas British and Northern American adolescents reported the highest levels of weekly MVPA with an average of 4.5 days.

Across age, exceeding the $2 \mathrm{hr}$ recommendation for cumulative screen-time was found to be most prevalent among 15yr-olds. 13yr-olds more commonly exceed $2 \mathrm{hrs}$ daily watching TV or by playing TV/PC games while more $15 y$ r-olds reported more than 2 hrs daily using the computer for non-gaming purposes. While mean levels of VPA appear to have a slight peak at age 13, MVPA shows a clear decline with age.

Table 2 shows the pooled regional and the total pooled effects of regressing weekly MVPA and VPA on the dummy variables indicating whether individuals exceed 2 hrs daily in both cumulative and individual screen-based sedentary behaviors. Results show significant negative associations between exceeding $2 \mathrm{hrs}$ of cumulative screen-time and MVPA among both boys and girls, while associations for VPA were significant for girls only. As the MVPA coefficients refer to predicted change in days per week of 60 minutes of MVPA, the pooled estimates indicate that girls who exceed 2 hrs daily of cumulative screen use report doing 60 minutes of MVPA on average .21 days less per week (one whole day less pr 5 weeks), the overall pooled effect for boys translates into .16 days less weekly. The predicted decrease in weekly VPA for girls exceeding 2 hrs cumulative screen-use is 5.4 minutes. The strongest negative associations were found in North America where exceeding 2 hrs cumulative screen time was associated with more than half-an-hour less of VPA weekly for both boys and girls, and with a predicted decrease of one half day per week of 60 minutes MVPA for both genders.

When investigating the individual screen-behaviors, more than 2 hrs daily of TV viewing showed the same pattern as cumulative screen-time, and gaming was negatively associated with both MVPA and VPA for boys. Non-gaming computer use was weakly positively associated with VPA for both genders. Regionally, there were stronger negative associations between all screen-based behaviors (except gaming for boys) in North America and the Nordic countries. In contrast, associations were generally positive or non-significant for East and Southern Europe.

The I-square statistic as presented by Higgins and Thompson [23] showed that the percentage of variation attributable to heterogeneity across the countries ranged from $16-88 \%$, with the majority above $50 \%$. All heterogeneity statistics were statistically significant $(\mathrm{p}<.05)$.

The bivariate correlations between the independent variables were all small or moderate $(r=.21$ to $r=.39)$ suggesting little that the risk of bias in the results due to multicollinearity.

Table 3 shows results from meta-regression analyses aiming to investigate whether the associations between physical activity and screen-based sedentary behaviors are systematically associated with national mean levels of these behaviors. The two models: "Screen time on MVPA" and "Screen time on VPA" show the prediction of the associations between exceeding $2 \mathrm{hrs}$ in cumulative screen-time in MVPA and VPA respectively. All associations between exceeding cumulative screen time and both VPA and MVPA were significantly associated with national mean levels of physical activity. Mean national levels of screen-based sedentary behaviors were not significantly associated with these estimates. This indicates that stronger negative associations between screen-based sedentary behaviors and physical activity were generally found in countries where adolescents were more physically active. Mean national levels of physical activity were also found to have significant associations with the associations of the individual screen-based behaviors.

\section{Discussion}

There was considerable heterogeneity across regions in the associations between exceeding 2 hrs daily in screenbased sedentary behaviors and levels of both VPA and MVPA. The variation in strength and direction of the associations between physical activity and the different screen-based sedentary behaviors supports Biddle and colleagues [24] suggesting that the various screen-based sedentary behaviors should be considered as qualitatively different behaviors. The results also show that levels of physical activity and screen-based sedentary behaviors differ between gender, age and geographical regions.

Inter-regional differences suggest that the strongest negative associations between physical activity and screen-based sedentary behaviors were found in North America and the Nordic countries. In these regions, exceeding guidelines for screen-based sedentary behavior was associated with meeting the recommended $60 \mathrm{~min}$ utes daily of MVPA [25] on average one half day less per week and about half an hour less of VPA weekly relative to not exceeding guidelines. In the British Isles, Central Europe and the Baltic countries associations were the more moderate suggesting that exceeding the recommendations is generally also associated with less physical activity, whereas the associations tended to be either nonsignificant or positive in the Southern and Eastern European countries. 
Table 2: Region stratified and pooled estimates of change in weekly hrs of VPA days of 60 min MVPA regressed on exceeding 2 hrs daily total screen-time and in TV, Gaming, and PC use separately, controlled for age and family affluence

\begin{tabular}{|c|c|c|c|c|c|c|c|c|}
\hline & \multicolumn{4}{|c|}{ VPA } & \multicolumn{4}{|c|}{ MVPA } \\
\hline & ES & $95 \% \mathrm{Cl}$ & ES & $95 \% \mathrm{Cl}$ & ES & $95 \% \mathrm{Cl}$ & ES & $95 \% \mathrm{Cl}$ \\
\hline & Boy & & Girl & & Boy & & Girl & \\
\hline \multicolumn{9}{|l|}{$\begin{array}{l}\text { Cumulative } \\
\text { screen }\end{array}$} \\
\hline $\begin{array}{r}\text { North } \\
\text { America }\end{array}$ & -0.58 & $(-0.77$ to -0.38$)$ & -0.57 & $(-0.72$ to -0.42$)$ & -0.54 & $(-0.70$ to -0.38$)$ & -0.42 & $(-0.55$ to -0.29$)$ \\
\hline $\begin{array}{r}\text { Nordic } \\
\text { Countries }\end{array}$ & -0.51 & $(-0.63$ to -0.38$)$ & -0.36 & $(-0.45$ to -0.28$)$ & -0.47 & $(-0.57$ to -0.37$)$ & -0.46 & $(-0.54$ to -0.38$)$ \\
\hline British Isles & -0.31 & $(-0.45$ to -0.16$)$ & -0.26 & $(-0.36$ to -0.16$)$ & -0.31 & $(-0.41$ to -0.20$)$ & -0.27 & $(-0.36$ to -0.18$)$ \\
\hline $\begin{array}{l}\text { Central } \\
\text { Europe }\end{array}$ & 0.01 & $(-0.08$ to 0.10$)$ & -0.21 & $(-0.29$ to -0.14$)$ & -0.22 & $(-0.29$ to -0.14$)$ & -0.21 & $(-0.29$ to -0.14$)$ \\
\hline $\begin{array}{r}\text { Baltic } \\
\text { Countries }\end{array}$ & 0.12 & $(-0.05$ to 0.30$)$ & -0.15 & $(-0.26$ to -0.03$)$ & -0.21 & $(-0.38$ to -0.04$)$ & -0.30 & $(-0.42$ to -0.17$)$ \\
\hline $\begin{array}{l}\text { Eastern } \\
\text { Europe }\end{array}$ & 0.13 & (0.05 to 0.22 ) & -0.01 & $(-0.07$ to 0.05$)$ & -0.08 & $(-0.16$ to 0.01$)$ & -0.15 & $(-0.22$ to -0.08$)$ \\
\hline South Europe & 0.29 & (0.22 to 0.36$)$ & 0.12 & (0.07 to 0.17 ) & 0.13 & (0.06 to 0.20 ) & -0.02 & $(-0.08$ to 0.04$)$ \\
\hline pooled ES & 0.03 & $(-0.01$ to 0.07$)$ & -0.09 & $(-0.12$ to -0.06$)$ & -0.16 & $(-0.20$ to -0.13$)$ & -0.21 & $(-0.24$ to -0.18$)$ \\
\hline \multicolumn{9}{|l|}{ TV } \\
\hline $\begin{array}{r}\text { North } \\
\text { America }\end{array}$ & -0.39 & $(-0.54$ to -0.24$)$ & -0.46 & $(-0.58$ to -0.35$)$ & -0.29 & $(-0.41$ to -0.16$)$ & -0.32 & $(-0.44$ to -0.19$)$ \\
\hline $\begin{array}{r}\text { Nordic } \\
\text { Countries }\end{array}$ & -0.27 & $(-0.36$ to -0.19$)$ & -0.30 & $(-0.37$ to -0.22$)$ & -0.18 & $(-0.26$ to -0.10$)$ & -0.41 & $(-0.48$ to -0.33$)$ \\
\hline British Isles & -0.07 & $(-0.17$ to 0.03$)$ & -0.20 & $(-0.29$ to -0.11$)$ & -0.16 & $(-0.24$ to -0.07$)$ & -0.20 & $(-0.28$ to -0.12$)$ \\
\hline $\begin{array}{l}\text { Central } \\
\text { Europe }\end{array}$ & 0.01 & $(-0.07$ to 0.09$)$ & -0.22 & $(-0.29$ to -0.15$)$ & -0.06 & $(-0.13$ to 0.01$)$ & -0.18 & $(-0.25$ to -0.10$)$ \\
\hline $\begin{array}{r}\text { Baltic } \\
\text { Countries }\end{array}$ & -0.03 & $(-0.14$ to 0.08$)$ & -0.09 & $(-0.17$ to 0.00$)$ & -0.05 & $(-0.14$ to 0.05$)$ & -0.16 & $(-0.26$ to -0.07$)$ \\
\hline $\begin{array}{l}\text { Eastern } \\
\text { Europe }\end{array}$ & 0.12 & (0.05 to 0.18 ) & -0.06 & $(-0.11$ to -0.01$)$ & 0.01 & $(-0.06$ to 0.07$)$ & -0.21 & $(-0.27$ to -0.14$)$ \\
\hline South Europe & 0.19 & (0.13 to 0.25 ) & 0.02 & (-0.03 to 0.07$)$ & 0.10 & (0.05 to 0.16$)$ & -0.07 & $(-0.13$ to -0.02$)$ \\
\hline Pooled ES & 0.02 & $(-0.01$ to 0.05$)$ & -0.12 & $(-0.14$ to -0.09$)$ & -0.05 & $(-0.07$ to -0.02$)$ & -0.20 & $(-0.22$ to -0.17$)$ \\
\hline \multicolumn{9}{|l|}{ Game } \\
\hline $\begin{array}{r}\text { North } \\
\text { America }\end{array}$ & -0.59 & $(-0.79$ to -0.38$)$ & -0.14 & $(-0.35$ to 0.06$)$ & -0.38 & $(-0.54$ to -0.21$)$ & -0.35 & $(-0.56$ to -0.15$)$ \\
\hline $\begin{array}{r}\text { Nordic } \\
\text { Countries }\end{array}$ & -0.59 & $(-0.74$ to -0.44$)$ & -0.31 & $(-0.46$ to -0.16$)$ & -0.58 & $(-0.66$ to -0.50$)$ & -0.06 & $(-0.21$ to 0.08$)$ \\
\hline British Isles & -0.27 & $(-0.41$ to -0.13$)$ & -0.14 & $(-0.28$ to 0.00$)$ & -0.17 & $(-0.27$ to -0.07$)$ & 0.03 & $(-0.11$ to 0.16$)$ \\
\hline $\begin{array}{l}\text { Central } \\
\text { Europe }\end{array}$ & -0.17 & $(-0.29$ to -0.05$)$ & -0.06 & $(-0.18$ to 0.06$)$ & -0.22 & $(-0.31$ to -0.14$)$ & -0.08 & $(-0.2$ to 0.04$)$ \\
\hline $\begin{array}{r}\text { Baltic } \\
\text { Countries }\end{array}$ & -0.05 & $(-0.20$ to 0.10$)$ & -0.11 & $(-0.26$ to 0.04$)$ & -0.17 & $(-0.28$ to -0.06$)$ & -0.04 & $(-0.20$ to 0.13$)$ \\
\hline $\begin{array}{l}\text { Eastern } \\
\text { Europe }\end{array}$ & 0.05 & $(-0.04$ to 0.14$)$ & 0.08 & $(-0.01$ to 0.17$)$ & -0.11 & $(-0.18$ to -0.04$)$ & 0.02 & $(-0.08$ to 0.12$)$ \\
\hline South Europe & 0.10 & (0.01 to 0.19 ) & 0.03 & $(-0.06$ to 0.12$)$ & 0.03 & $(-0.04$ to 0.10$)$ & 0.08 & $(-0.02$ to 0.18$)$ \\
\hline Pooled ES & -0.10 & $(-0.15$ to -0.06$)$ & -0.04 & $(-0.09$ to 0.00$)$ & -0.20 & $(-0.23$ to -0.17$)$ & -0.02 & $(-0.07$ to 0.03$)$ \\
\hline
\end{tabular}


Table 2: Region stratified and pooled estimates of change in weekly hrs of VPA days of 60 min MVPA regressed on exceeding 2 hrs daily total screen-time and in TV, Gaming, and PC use separately, controlled for age and family affluence (Continued)

\begin{tabular}{|c|c|c|c|c|c|c|c|c|}
\hline \multicolumn{9}{|l|}{ PC } \\
\hline $\begin{array}{r}\text { North } \\
\text { America }\end{array}$ & 0.20 & (0.03 to 0.38 ) & -0.17 & $(-0.33$ to -0.02$)$ & 0.21 & (0.06 to 0.36 ) & 0.01 & $(-0.12$ to 0.15$)$ \\
\hline $\begin{array}{r}\text { Nordic } \\
\text { Countries }\end{array}$ & -0.09 & $(-0.19$ to 0.01$)$ & -0.20 & $(-0.29$ to -0.11$)$ & -0.10 & $(-0.19$ to -0.01$)$ & -0.22 & $(-0.31$ to -0.13$)$ \\
\hline British Isles & 0.07 & $(-0.05$ to 0.20$)$ & 0.00 & (-0.11 to 0.11$)$ & -0.05 & $(-0.16$ to 0.06$)$ & -0.08 & $(-0.18$ to 0.03$)$ \\
\hline $\begin{array}{l}\text { Central } \\
\text { Europe }\end{array}$ & 0.10 & (0.00 to 0.20$)$ & -0.01 & $(-0.10$ to 0.09$)$ & 0.10 & (0.01 to 0.19 ) & -0.07 & $(-0.16$ to 0.02$)$ \\
\hline $\begin{array}{r}\text { Baltic } \\
\text { Countries }\end{array}$ & 0.16 & (0.02 to 0.31 ) & 0.16 & (0.03 to 0.28 ) & -0.02 & $(-0.15$ to 0.11$)$ & -0.04 & $(-0.16$ to 0.08$)$ \\
\hline $\begin{array}{l}\text { Eastern } \\
\text { Europe }\end{array}$ & 0.19 & (0.10 to 0.28 ) & 0.19 & (0.11 to 0.26 ) & 0.11 & (0.02 to 0.21$)$ & 0.12 & (0.03 to 0.22 ) \\
\hline South Europe & 0.21 & (0.12 to 0.30$)$ & 0.21 & (0.14 to 0.28 ) & 0.03 & $(-0.05$ to 0.12$)$ & 0.06 & $(-0.02$ to 0.14$)$ \\
\hline Pooled ES & 0.12 & (0.08 to 0.16$)$ & 0.07 & $(0.03$ to 0.10$)$ & 0.03 & $(-0.01$ to 0.01$)$ & -0.03 & $(-0.07$ to 0.00$)$ \\
\hline
\end{tabular}

Contrary to the displacement hypothesis [6], this study did not reveal a higher level of displacement in countries where adolescents spend more time in screen-based sedentary behaviors. Instead, stronger negative associations between physical activity and screen-based sedentary behaviors are found in countries where the level of physical activity is relatively high. This may be interpreted to indicate that physical inactivity is not a consequence of adolescents spending too much time in screen-based sedentary behaviors, but rather that inactive adolescents have more time spend in different sedentary pursuits. The stronger negative association between physical activity and TV for girls vs. gaming for boys may thus simply reflect that inactive girls tend to watch more TV while inactive boys tend to spend more time playing computer games.

The overall positive associations between non-gaming computer use and physical activity also suggests that using the computer for homework and other such purposes is not likely to displace time for physical activity. Consequently, the current results do not support the inclusion of this type of behavior in national recommendations.

The descriptive results suggest that boys spend more time than girls, both in screen-based sedentary behaviors and in physical activity. This is comparable to a number of other studies investigating gender differences in screen-based behaviors [26-28] and physical activity

Table 3: Meta-regression regressing level of displacement a on national mean levels of physical activity and screen-based sedentary behaviors.

\begin{tabular}{|c|c|c|c|c|c|c|}
\hline & \multicolumn{2}{|c|}{ Boys } & \multicolumn{4}{|c|}{ Girls } \\
\hline & Coef & $\mathbf{9 5} \% \mathrm{Cl}$ & $\mathbf{R 2}$ & Coef & $95 \% \mathrm{Cl}$ & $\mathbf{R} 2$ \\
\hline \multicolumn{7}{|l|}{$\begin{array}{l}\text { Screen time } \\
\text { on MVPA }\end{array}$} \\
\hline 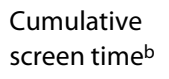 & 0.06 & $(-0.04$ to 0.15$)$ & 30.45 & -0.03 & $(-0.09$ to 0.02$)$ & 47.41 \\
\hline Mean MVPAc & -0.41 & $(-0.64$ to- 0.18$)$ & & -0.27 & $(-0.41$ to -0.12$)$ & \\
\hline \multicolumn{7}{|l|}{$\begin{array}{l}\text { Screen time } \\
\text { on VPA }\end{array}$} \\
\hline $\begin{array}{l}\text { Cumulative } \\
\text { screen time }\end{array}$ & 0.07 & $(-0.04$ to 0.19$)$ & 36.55 & 0.01 & $(-0.07$ to 0.08$)$ & 48.11 \\
\hline Mean VPA ${ }^{d}$ & -0.37 & $(-0.57$ to -0.18$)$ & & -0.25 & $(-.37$ to -0.12$)$ & \\
\hline
\end{tabular}

Note. (a) country estimates of the association between physical activity and screen-based sedentary behaviors; (b) refers to the mean cumulative time spent in screen-based sedentary behavior for each respective country; (c) refers to the mean number of days pr week with 60 minutes cumulative MVPA in each country; (d) refers to the mean number of hours pr week in vigorous physical activity in each country. 
$[13,29,30]$. The tendency for boys to report to spend more time than girls in all these behaviors could reflect a gender related reporting bias, or simply that girls spend their leisure time doing activities not assessed by this type of survey.

Age differences show that older adolescents are more likely to be spending more than 2 hrs daily in cumulative screen-time. A similar development is evident for nongaming computer use, while high use of both TV and gaming peak at $13 y r s$. This development may partially be due to a change in preference as adolescents grow older, but it is also likely that demands and/or opportunities for using computers for schoolwork among older students may be a contributing factor for the increase in this type of computer use across age.

The different types of physical activity also show different patterns across age. While the identified decrease in MVPA across age is supported by previous research [3134], the overall mean levels of reported VPA appeared stable with a slight peak among the 13-year olds.

The prevalences of TV watching in the current study correspond well with the review done by Marshall and colleagues [28] who found an overall prevalence of $66 \%$ across the reviewed studies. The corresponding prevalence in the current results is 59\% (41\% exceed $2 \mathrm{hrs).}$

Even though the reported time spent in the different behaviors should be interpreted with caution as both VPA and time spent watching TV are typically overreported [17,35] and MVPA often is under-reported [36], the current results reveal a consistent pattern of more favorable levels of both VPA and sedentary behaviors in the Northern and Central European countries compared to Southern and Eastern Europe.

There are some limitations to this study. The cross-sectional design limits the extent to which causal relationships can be assessed and the validity of self-report measures assessing the time spent in various activities is not thoroughly investigated. However, even if the item validity is judged critically, there is evidence suggesting relative validity of the items used $[17,18,37]$.

Another limitation which may have implications for the study is that the time periods in which the different behaviors are assessed are not completely consistent. While the question about VPA specified the time frame to be "outside school-hours", questions about screenbehaviors were during "free-time". This is relevant as homework, chores, work, or other obligations are done outside school-hours, but may not be considered to be "free-time". Although these behaviors were not assessed in the HBSC survey, they should be recognized as potential confounders when interpreting the current results.

Strengths of the study include the vast sample size and the regional comparisons which have previously not been reported in the scientific literature. The methodological approach is also well suited to such a large sample as the presentation of results by regions provides both a rough overview while still providing sufficient details for interpretation.

Despite limitations, this study has several potential implications shedding new light on the relationship between physical activity and screen-based sedentary behavior. First and foremost, it shows that the guidelines for limiting screen-based sedentary behaviors as implemented in the US and Australia may not be conducive to promoting physical activity in all countries. Secondly, it highlights the importance of both local and crossnational epidemiological research. The differences across countries illustrate that single country studies would have yielded different results which in turn could lead authors to conclude differently and suggest implications and recommendations based upon biased results.

The potential health promoting benefits of reducing screen-based sedentary behaviors have been highlighted by results from smaller scale interventions. A study by Epstein and colleagues [38] found that increasing screenbased sedentary behaviors was associated with lower levels of physical activity and increased caloric intake for non-obese children. The reduction of screen-based sedentary behaviors has also been associated with positive changes in physiological measurements such as BMI and waist circumference in elementary school children [39]. However, it is uncertain whether such results could be reproduced in larger scale interventions.

Examples of future research designs that would compliment the current results could include the use of objective assessments of physical activity such as actigraphs. Validation studies or alternative or improved ways of measuring screen-based sedentary behavior would also be valuable. There is also a need for more knowledge about how both environmental and motivational factors influence children and adolescents' use of screen-based sedentary behaviors.

\section{Conclusions}

The current study has shown that spending more than 2 hrs daily in screen-based sedentary behaviors is not consistently associated with lower levels of physical activity across genders and geographical regions. This suggests that the guidelines which are implemented in the US [10] and in Australia [11] may not be appropriate in all regions as a tool to increase levels of physical activity in the adolescent population. More importantly, the regional differences identified in this study highlight the necessity of cross national studies, suggesting that conclusions based upon local or even nationally representative studies may not be universally generalizable. 


\section{Additional material}

Additional file 1 Percentage of adolescents who exceed 2 hrs daily of screen based sedentary behaviors and mean levels of Physical activity across countries, age and gender

\section{Competing interests}

The authors declare that they have no competing interests.

\section{Authors' contributions}

All analyses as well as written sections of the manuscript were mainly done by $\mathrm{OM}$. TT as the main supervisor of the project have given the first author essential feedback and advice at all stages of producing this manuscript. BW and RI have contributed significantly with comments and suggestions throughout the writing process. All authors read and approved the final manuscript.

\section{Acknowledgements}

HBSC is an international study carried out in collaboration with WHO/EURO. The international coordinator of the 2001-2002 and 2005-2006 study was Candace Currie, University of Edinburgh, Scotland; and the data bank manager was Oddrun Samdal, University of Bergen, Norway. A complete list of the participating researchers can be found on the HBSC website http://www.HBSC.org.

\section{Author Details}

1 University of Bergen, Faculty of Psychology, Christiesgate 13, N-5015 Bergen, Norway and 2NICHD - National Institute of Child Health and Human Development 6100 Executive boulevard, 7B05 Bethesda MD20892-7510, USA

Received: 9 July 2009 Accepted: 21 May 2010

Published: 21 May 2010

\section{References}

1. Elgar FJ, Roberts C, Moore L, Tudor-Smith C: Sedentary behaviour, physical activity and weight problems in adolescents in Wales. Public Health 2005, 119(6):518-524

2. Utter J, Neumark-Sztainer D, Jeffery R, Story M: Couch potatoes or french fries: Are sedentary behaviors associated with body mass index, physical activity, and dietary behaviors among adolescents? Journal of the American Dietetic Association 2003, 103(10):1298-1305

3. Ekelund U, Brage S, Froberg K, Harro M, Anderssen SA, Sardinha LB, Riddoch C, Andersen LB: TV viewing and physical activity are independently associated with metabolic risk in children: The European Youth Heart Study. Plos Medicine 2006, 3(12):2449-2457.

4. Strong WB, Malina RM, Blimkie CJR, Daniels SR, Dishman RK, Gutin B, Hergenroeder AC, Must A, Nixon PA, Pivarnik JM, Rowland T, Trost S, Trudeau FO: Evidence based physical activity for school-age youth. Journal of Pediatrics 2005, 146(6):732-737

5. Biddle SJH, Gorely T, Stensel DJ: Health-enhancing physical activity and sedentary behaviour in children and adolescents. Journal of Sports Sciences 2004, 22(8):679-701.

6. Vandewater EA, Shim MS, Caplovitz AG: Linking obesity and activity level with children's television and video game use. Journal of Adolescence 2004, 27(1):71-85

7. Durant RH, Baranowski T, Johnson M, Thompson WO: The Relationship among Television Watching, Physical-Activity, and Body-Composition of Young-Children. Pediatrics 1994, 94(4):449-455.

8. Warburton DER, Nicol CW, Bredin SSD: Health benefits of physical activity: the evidence. Canadian Medical Association Journal 2006, 174(6):801-809.

9. Marshall SJ, Biddle SJH, Gorely T, Cameron N, Murdey I: Relationships between media use, body fatness and physical activity in children and youth: a meta-analysis. International Journal of Obesity 2004, 28(10):1238-1246

10. Bar-on ME, Broughton DD, Buttross S, Corrigan S, Gedissman A, de Rivas MRG, Rich M, Shifrin DL, Educ C: Children, adolescents, and television. Pediatrics 2001, 107(2):423-426.

11. Australia's Physical Activity Recommendations from 12-18 year olds. Department of Health and Aging: Canberra; 2004.

12. Janssen I, Katzmarzyk PT, Boyce WF, Vereecken C, Mulvihill C, Roberts C, Currie C, Pickett W, Grp HBSACOW: Comparison of overweight and obesity prevalence in school-aged youth from 34 countries and their relationships with physical activity and dietary patterns. Obesity Reviews 2005, 6(2):123-132.

13. Samdal O, Tynjala J, Roberts C, Sallis JF, Villberg J, Wold B: Trends in vigorous physical activity and TV watching of adolescents from 1986 to 2002 in seven European Countries. European Journal of Public Health 2007, 17(3):242-248

14. Currie CE, Roberts C, Morgan A, Smith R, Settertobulte W, Samdal O, Rasmussen VB, eds: Young People's Health in Context. Health Behaviour in School-aged Children: A WHO Cross-National Collaborative Study (HBSC International Report from the 2001/02 Survey). Healthy Policy for Children and Adolescents 2004.

15. Roberts C, Freeman J, Samdal O, Schnohr CW, de Looze ME, Gabhainn SN, lannotti R, Rasmussen M, Grp IHS: The Health Behaviour in School-aged Children (HBSC) study: methodological developments and current tensions. International Journal of Public Health 2009, 54:140-150.

16. Currie C, Gabhainn SN, Godeau E, Comm IHNC: The Health Behaviour in School-aged Children: WHO Collaborative Cross-National (HBSC) Study: origins, concept, history and development 1982-2008. International Journal of Public Health 2009, 54:131-139.

17. Vereecken CA, Todd J, Roberts C, Mulvihill C, Maes L: Television viewing behaviour and associations with food habits in different countries. Public Health Nutrition 2006, 9(2):244-250.

18. Booth ML, Okely AD, Chey T, Bauman A: The reliability and validity of the physical activity questions in the WHO health behaviour in schoolchildren (HBSC) survey: a population study. British Journal of Sports Medicine 2001, 35(4):263-267.

19. Prochaska JJ, Sallis JF, Long B: A physical activity screening measure for use with adolescents in primary care. Archives of Pediatrics \& Adolescent Medicine 2001, 155(5):554-559.

20. Currie C, Molcho M, Boyce W, Holstein B, Torsheim T, Richter M: Researching health inequalities in adolescents: The development of the Health Behaviour in School-Aged Children (HBSC) Family Affluence Scale. Social Science \& Medicine 2008, 66(6):1429-1436.

21. Andersen A, Krolner R, Currie C, Dallago L, Due M, Richter, Okenyi A, Holstein BE: High agreement on family affluence between children's and parents' reports: international study of 11-year-old children. Journal of Epidemiology and Community Health 2008, 62(12):1092-1094.

22. Harris RJ, Bradburn MJ, Deeks JJ, Harbord RM, Altman DG, Sterne JAC: metan: fixed- and random-effects meta-analysis. Stata Journal 2008 , 8(1):3-28.

23. Higgins JPT, Thompson SG: Quantifying heterogeneity in a metaanalysis. Statistics in Medicine 2002, 21(11):1539-1558.

24. Biddle SJH, Gorely T, Marshall SJ, Murdey I, Cameron N: Physical activity and sedentary behaviours in youth: issues and controversies. Journal of the Royal Society for the Promotion of Health 2004, 124(1):29-33.

25. Cavill N, Biddle S, Sallis JF: Health enhancing physical activity for young people: Statement of the United Kingdom Expert Consensus Conference. Pediatric Exercise Science 2001, 13(1):12-25

26. Colley A, Comber C: Age and gender differences in computer use and attitudes among secondary school students: what has changed? Educational Research 2003, 45(2):155-165.

27. Cummings HM, Vandewater EA: Relation of adolescent video game play to time spent in other activities. Archives of Pediatrics \& Adolescent Medicine 2007, 161(7):684-689.

28. Marshall SJ, Gorely T, Biddle SJH: A descriptive epidemiology of screenbased media use in youth: A review and critique. Journal of Adolescence 2006, 29(3):333-349.

29. Brodersen NH, Steptoe A, Boniface DR, Wardle J: Trends in physical activity and sedentary behaviour in adolescence: ethnic and socioeconomic differences. British Journal of Sports Medicine 2007, 41(3):140-144

30. Riddoch CJ, Andersen LB, Wedderkopp N, Harro M, Klasson-Heggebo L, Sardinha LB, Cooper AR, Ekelund U: Physical activity levels and patterns of 9-and 15-yr-old European children. Medicine and Science in Sports and Exercise 2004, 36(1):86-92.

31. Pate RR, Freedson PS, Sallis JF, Taylor WC, Sirard J, Trost SG, Dowda M: Compliance with physical activity guidelines: Prevalence in a population of children and youth. Annals of Epidemiology 2002, 12(5):303-308. 
32. Nelson MC, Neumark-Stzainer D, Hannan PJ, Sirard JR, Story M: Longitudinal and secular trends in physical activity and sedentary behavior during adolescence. Pediatrics 2006, 118(6):E1627-E1634.

33. Kjonniksen L, Torsheim T, Wold B: Tracking of leisure-time physical activity during adolescence and young adulthood: a 10-year longitudinal study. International Journal of Behavioral Nutrition and Physical Activity 2008, 5:

34. Telama R, Yang XL, Viikari J, Valimaki I, Wanne O, Raitakari O: Physical activity from childhood to adulthood - A 21-year tracking study. American Journal of Preventive Medicine 2005, 28(3):267-273.

35. Sallis JF, Saelens BE: Assessment of physical activity by self-report: Status, limitations, and future directions (vol 71, pg 1, 2000). Research Quarterly for Exercise and Sport 2000, 71(4):409-409.

36. Armstrong N, Welsman JR: The physical activity patterns of European youth with reference to methods of assessment. Sports Medicine 2006 36(12):1067-1086

37. Rangul V, Holmen TL, Kurtze N, Cuypers K, Midthjell K: Reliability and validity of two frequently used self-administered physical activity questionnaires in adolescents. Bmc Medical Research Methodology 2008, 8:

38. Epstein LH, Paluch RA, Consalvi A, Riordan K, Scholl T: Effects of manipulating sedentary behavior on physical activity and food intake. Journal of Pediatrics 2002, 140(3):334-339.

39. Robinson TN: Reducing children's television viewing to prevent obesity - A randomized controlled trial. Jama-Journal of the American Medical Association 1999, 282(16):1561-1567.

doi: 10.1186/1479-5868-7-46

Cite this article as: Melkevik et al, Is spending time in screen-based sedentary behaviors associated with less physical activity: a cross national investigation International Journal of Behavioral Nutrition and Physical Activity 2010, 7:46

Submit your next manuscript to BioMed Centra and take full advantage of:

- Convenient online submission

- Thorough peer review

- No space constraints or color figure charges

- Immediate publication on acceptance

- Inclusion in PubMed, CAS, Scopus and Google Scholar

- Research which is freely available for redistribution

Submit your manuscript at www.biomedcentral.com/submit
C) BioMed Central 